\title{
Double Tragedy for Women with Disabilities in the Zimbabwean Education System.
}

\author{
Nyunyutai Mudzingwa \\ Zimbabwe Association Of The Visually Handicapped (ZAVH) \\ House number 19230, Nyamavhuvhu Street \\ Rujeko $1 \mathrm{C}$, Masvingo, Zimbabwe
}

\begin{abstract}
Disability is about discrimination and systematic exclusion. This is aggravated in the case of women with disabilities in developing countries. Women with disabilities face attitudinal, physical and financial barriers in life. They face challenge in three broad and distinguished angles: as women in general, as people with disabilities and as women with disabilities. Therefore, being a woman with a disability is a double tragedy. This study seeks to examine the double tragedy of women with disabilities in the Zimbabwean education system. Forty-three female participants with disabilities gave their responses to the questions laid out in the questionnaire given to them in Chivi District. These participants were of different ages with different levels of education. They were given the opportunity to freely respond to the questions. The results indicated that due to marginalization and stigmatization, women with disabilities were denied access to education right from the beginning. Very few of them, went to school and managed to accomplish their goals. It is recommended that, the state and the stakeholders should empower women with disabilities in Zimbabwe. Women with disabilities should liberate themselves by revealing their potential in their communities and society at large. Of the forty-three respondents in Chivi district: ten of them never went to school. Thirteen of them had not gone as far as grade seven level. Six of them completed primary level. Three attained ZJC level nine 0 -level, two of them obtained a professional certificate and none of them attained A-level, Diploma, first Degree or Masters Degree.
\end{abstract}

Keyword: terms-women with disabilities, double tragedy, discrimination.

\section{BACKGROUND}

There are many cultural, social, educational and economic factors that surround women with disabilities in Zimbabwe. Women with disabilities have social participation restrictions which are enhanced by the cultural practices in their communities. They are stigmatized by relatives and community members. If the family of her birth and close relatives welcome her the better, because in most cases, even her parents desert her totally. If one is not accepted by the family and close relatives, members of the community will not gain access to that person. In some instances girls with disabilities are kept indoors keeping them from interacting with the members of their community. These women are in double tragedy because neither their immediate family nor the community can rescue them from their plight. The reasons being that the family feels that it is unfortunate in having such a child, and because the community members know nothing about the child they can not intervene to rescue them. For example if teachers and heads of schools would come to know about the marginalized girls in their communities they would intervene, for them to come out of that awful situation, by advising the parents to sent this child to the relevant special institutions. For example Henry Murray school for the deaf ,King George (vi) for those with physical challenge and Copota School for the blind. 
The worst scenario is that, they also suffer from self-stigma, emanating from the way other members of the society see them (Global Health Action, 2012). Sociologists believe that socialization is a lifelong process of internalizing culture and learning necessary behaviour to function in a given society. Every baby is socialized into a particular culture with its beliefs, customs, norms and values. If a baby grows up in the environment where he or she is despised and degraded he or she is likely to grow up believing that he/she is as inferior as society has portrayed. Women with disabilities cannot run away from self-stigma if they live in the society that looks down upon them. This is indeed a double tragedy. If society would change and begin to accept women with disabilities, I believe, they would also start to see themselves with a different eye, realize their self worth.However there are some women with disabilities who despite negative social attitudes, managed to go as far as the University level. Again, being in a patriarchal society where men are heads and all women subordinates, women with disabilities cannot escape from such abuse. This is indeed a double tragedy. Existing in the environment where they are despised and looked down upon, they end up losing confidence in themselves. They feel inferior and unwanted in society.

Women with disabilities make very few choices that pertain to their own lives. Carers become unacceptably powerful making decisions about what is best for them. An extreme, though not uncommon example of this, is the enforced sterilization without consultation or consent of women with disabilities, (Harris 2003 ). If women with disabilities are not given the opportunity to choose what they want in these other social activities, certainly they are not given room to choose whether to go to school or not. Their carers make choices for them. In the past, it was culturally proper not to send a girl to school. With this scenario, it would be more acceptable not to send a girl with a disability to school and this would be a double tragedy for the woman with disability.

\section{CONCEPTUAL FRAMEWORK}

The United Nations Convention On The Rights Of Persons With Disabilities (UNCRPD,2006) established an agenda for change for all persons with disabilities .Focus was also on women with disabilities (Article 6).This international Covenant was adopted in the year (2006).It seeks to, promote ,protect and ensure the full and equal enjoyment of all Human Rights and Fundamental Freedoms by all persons with disabilities and to promote respect for their inherent dignity(UNCRPD, 2006 ).It had been recognized that people with disabilities had been marginalized from time immemorial. Women with disabilities ,are often at greater risk, both within and outside the home, of violence, injury or abuse, neglect or maltreatment or exploitation, (UNCRPD 2006).The implementation of this treaty is a requirement in order to improve the lives of people with disabilities in the whole world. The lives of women with disabilities should also be transformed. They should also attain the education that they need UNCRPD Article 24(2006).It is believed that the literacy rate for women with disabilities globally, is lower than that of males with disabilities. Very little research has been done on the education of women with disabilities in Zimbabwe let alone Africa and the whole world. In the early 1990's, UNESCO estimated that perhaps 97 percent of the world's 650 million disabled persons were unable to read or write... These people have never seen the door of the classroom, resulting in the lowering of literacy rate for adults with disabilities in developing countries to as low as 3 percent and for women with disabilities to 1 percent, (Helander 1999 , cited in Singal 2013). If the literacy rate of women with disabilities is approximately 1 percent in the whole world, the percentage of the literacy rate of women with disabilities in developing countries is much less. This is a grey area which needs a lot of research. Zimbabwe statistics have it that there are over one million eight hundred thousand people with 
disabilities out of a population of about fifteen million, (NASCOH ,Harare).Having gathered all this information about women with disabilities one is bound to conclude that this constituency, which had been neglected for a long time, needs our attention.

\section{LITERATURE REVIEW}

The arrival of a baby with a disability in a family was, and is still unwelcome. Disability was considered a misfortune, a generally undesirable and unwelcome condition (Kauffman 1999). Ability was considered more desirable and acceptable than disability. The statements above explicitly bring out the fact that right from the beginning a child with a disability is different from other children, worse if the child is female. Society reacts to disability with horror, fear, anxiety, distaste, dislike and hostility, (Zim0 1981). If the family feels uncomfortable in the presence of a child with a disability, it would be worse for members of the community and society at large .They would feel more uncomfortable and horrified in the presence of children with disabilities. The Sub -Saharan languages consider a person with a disability as the borderline between a human being and a wild animal ( Devlieger 1998 ).This, in itself is extreme ignorance which needs to be corrected by persons with disabilities themselves, in their struggle to liberate themselves from such misconceptions and stereotypes.

People with disabilities are oppressed and marginalized in every country of the world with greater oppression on women with disabilities ( Coleridge2001). They are oppressed by negative social attitudes which come from fear and prejudice. In many developing countries, disability is often perceived by governments and Aid Agencies as a problem and not a priority, a liability and not an assert (Coleridge 2001 ). If they are a problem, a liability and not an asset the implication is that they can be ignored altogether in the development debate. Against this background, it has been discovered that the voice of people with disabilities themselves, women with disabilities in particular has hardly been heard( Coleridge 2001).

Disabled women in Zimbabwe and all developing countries face challenges in three broad and distinguished areas: They face challenges as women in general, as disabled people and as disabled women. Just because one is a woman she is bound to suffer the way other women do. For example, in the past, girls were not allowed to go to school. This would include girls with disabilities because of gender. All girls despite their outward appearance would be denied access to education. Therefore women with disabilities have issues in common with other women in their communities. That is where double tragedy comes in. Disabled women have issues in common with non-disabled women( Harris 2003).In our culture women are considered as weaker vessels .For example if girls are not encouraged to do manual work at school, then it may be considered a taboo to see a girl with a disability doing manual work at school, for example digging in the garden, however, all girls should be given room to do manual work both at home and at school.

Women with disabilities have issues in common with men with disabilities because both groups have the unique outward appearance(impairment). Just because one has an impairment, society reacts to that person in a peculiar manner. This is double tragedy for women with disabilities. They suffer together with men, because they fall in the same group defined by impairment. On top of their own challenges as women with disabilities, they share the problems of all women and those of men with disabilities. For example if the school head chooses not to enroll at the school all people with impairment, this will affect both females and males with disabilities. The fact that women with disabilities suffer together with other women and then share a common burden with males with disabilities, there is a double tragedy for them. Throughout the world, regardless of culture, people with disabilities have 
generally been considered as incapable of taking control of their own lives. This is inclusive of all people with disabilities in spite of gender, making females suffer together with males (Stuart 1992) They were seen as making no contribution to society and a drain to resources. If this applied to all persons with disabilities, women with disabilities would be in a worse state, which is double tragedy.

One of the challenges women with disabilities encounter is access to education. When we look at our cultural practices, women are accorded less opportunities than men especially in the area of education (Chimedza 2001). If these cultural practices affected all women, then this would mean that women with disabilities would be in a worse situation, for example when parents and guardians of children with disabilities encounter a crisis and would want o make a choice on who to send to school, a girl with a disability would come last. The hierarchy was like this, boys on top followed by girls, boys with disabilities and girls with disabilities at the very bottom of the ladder if at all they would be remembered.This is in itself a double tragedy and a disadvantage. The money that you have invested in the education of a woman will not benefit the family investment but another family, the one she joins after marriage (Chimedza 2001 ). Her parents would not want to educate her in preparation for her future which would benefit her new family, therefore girls were completely barred from going to school. This however was not supposed to affect women with disabilities. Since they were denied access to education, duties at home and other social activities, they were also not expected to marry. However this in itself, is a result of stigma, prejudices, misconceptions and marginilizations. Women with disabilities should therefore, be educated, because if they happen not to marry they become self reliant.If they marry, they can also be an asset to their new family breaking away from their double tragedy. Education is a prerequisite for productive employment. If an individual fails to attain education in his or her childhood, the implication is that employment opportunities become slim. In early childhood, all children with disabilities often get the message that they are unclean, inferior and unworthy of any education," (Chimedza 2001 ). Girls suffer more, in this state of affairs than boys. Young students with disabilities especially females, may need extra assistance in building their self-esteem or sense of self-worth," (Danforth and Rhodes, 1997)

The above information indicates that women with disabilities in Zimbabwe are in double tragedy. They are denied access to education, and, ultimately, are denied access to employment (Chimedza 2001) .Women with disabilities should liberate themselves from this ordeal. Freedom is acquired by conquest not by gift (Paulo Freire 1972).Freedom would require women with disabilities to eject this current self image and replace it with autonomy and responsibility (Paullo Freire 1972 ).It is possible for women with disabilities to attain their freedom, but the struggle begins with them.

\section{STATEMENT OF THE PROBLEM}

Women with disabilities suffer a double discrimination both on the grounds of gender and impairment. Women with disabilities in Zimbabwe have borne the yoke of social discrimination and exclusion. They have been denied access to full participation in the various social, economic, religious, political and educational activities in their communities and society at large for example, in the area of education. Due to prejudice, stigma and stereotypes from members of their communities, women with disabilities do not fully enjoy their Human Rights and fundamental Freedoms. They are treated as second class citizens in the country of their birth. They are flouted in some instances, by their closest siblings and parents. They are considered a misfortune, a bad omen and even a curse. The environment has forced them to 
lose their self-esteem. They have totally lost confidence in themselves. They are in real double tragedy. In this regard, their voice is not heard. Whilst other women's voices are heard .

\section{Participants and setting}

\section{METHODOLOGY}

The research was carried out in Masvingo Province, Chivi District. The actual areas visited by the researcher are: Mandamabwe, Uravi, Chivi Rural District Council and Maringire. Data was gathered from the forty-three females with disabilities of different ages. These respondents were drawn from the four age groups: 6---18, 19-30, 31---50, 50 and above.

\section{Research Design}

The researcher used the qualitative or descriptive method. She collected data from females with disabilities themselves. The qualitative method helped the researcher get clear information from the respondents. The respondents were also free to use the language they are comfortable with.

\section{Instrumentation}

The instrument used in the collection of data was the questionnaire. The researcher chose this instrument because it was not time-consuming and it motivated the respondents to provide complete and accurate information. The issue of anonymity was also encouraging to the respondents since they would not write their names in their responses. There were six questions for the participants. The researcher's intention was to establish the reasons why these women lived in such poverty. She wanted to know their age, level of education, reasons why they did not attain education and how this problem would be corrected. The researcher rephrased the questions in vernacular for the respondents to understand. The participants clearly expressed themselves in their responses.

\section{Procedure}

The writer obtained permission from Ministry of Education to make this research about double tragedy of women with disabilities in Zimbabwe. The letter of permission enabled the writer to visit places where the respondents were.

\section{Results}

The participants highlighted that they lived in abject poverty because they were not educated and ,therefore, failed to get meaningful employment to sustain themselves. Their parents and guardians chose to send other members of the family to school but not girls with disabilities. Their brothers and sisters were sent to school and they remained a forgotten group in the family. Some of them were sent to school, but did not get the opportunity to further their education to fulfill the desired goals. The reasons were that, they made slow progress, and encountered various hindrances on the way. For example: those with visual impairment found challenges in getting willing friends who would read literature in print for them. This caused underachievement on the part of these women with visual impairment. For women with physical challenge, whilst they could read and write in the acceptable format, the struggle they had in walking and in some instances, having to go upstairs for lessons, would in itself discourage them from pursuing their education. To substantiate this point, most children with physical challenge in a certain school in Harare indicated that they did not go for their Secondary education, because the classrooms were located upstairs, so the environment was inaccessible for them. Usually, males endured even in real difficulties, but as for women, most of them just dropped out of school because of lack of social support. Those female participants with mental challenge were mostly never bothered. Their parents and guardians 
saw it best to keep them at home because they thought there was no remedy in their case. The furthest level to be attained by one with mental challenge is grade seven. Female participants with albinism highlighted that they did not pursue their education, due to some limitations they encountered in the mainstream schools. The moment they discovered that they could not see information on the board like others, they got discouraged and dropped out of school. Nobody advised them to go to such institutions as Copota school for the blind where they would not have to use the chalkboard.

The researcher discovered that, ten of the respondents had never been to school. Thirteen of the participants had not gone as far as grade seven. Six of the female respondents went as far as grade seven level in their education. Only three, of the participants had attained a Zimbabwe Junior Certificate in education. Nine participants had completed O-level. Only two female respondents had a professional certificate. None of these female respondents had obtained an A-level certificate, Diploma, Degree and Masters Degree, let alone employment.

\section{DISCUSSION}

Our driving vision is of an inclusive world in which we are able to live a life of health, comfort and dignity. The results revealed that females with disabilities lived in abject poverty, which made it very difficult for them to accomplish this vision as people with disabilities in Zimbabwe. When one is poor, one cannot enjoy good health comfort and dignity. Since they depend on their families for shelter and financial resources, it becomes almost impossible for women with disabilities to live in comfort for example, good accommodation clothes and even education(UNCRPD 2006). The looking glass self theory asserts that, we imagine ourselves as others see us (Haralambos and Holborne 2001). The way women with disabilities are seen by members of society, is the same way they see themselves. If society tells them that they are inferior and useless they end up thinking in the same way. We are shaped the way others see us. Members of the community either raise one's self-esteem or lower it. Women with disabilities seem not to get encouragement from members of the society, so they engage in self-fulfilling prophecy (Giddens 2001).

On the issue of little or no education of females with disabilities which was revealed in the results, this emanated from the way they saw themselves. This is an indication of these participants' loss of self-esteem. They lacked self-motivation. In spite of all these negative attitudes from members of their communities and society at large, there are few women with disabilities, in Zimbabwe who achieved because of their intrinsic motivation . Females with disabilities occupied the lowest position in the hierarchy, where boys are at the top, of the ladder followed by girls, boys with disabilities and finally girls with disabilities. Results have shown us that ten of the respondents never went to school reasons might have emanated from this challenge. Boys, girls, and boys with disabilities were chosen in their place.

Results also reviewed that despite all these challenges, some females with disabilities did achieve for example those respondents,with professional qualifications who were self reliant.This in itself is a motivation to other females with disabilities to work hard for them to achieve.

With regards to the overall results above, most women with disabilities did not have education, which is a prerequisite for productive employment. There is little one can get from having qualifications below grade seven level as the thirteen participants in our findings. Even with the grade seven, form two and Ordinary level qualifications, due to high literacy rate in 
Zimbabwe, one would not get meaningful employment as the six , three and nine participants respectively in our results. This is an indication that women with disabilities are in double tragedy, because most of them do not have even the least academic qualifications that others have.

\section{CONCLUSION}

The results indicate that the majority of females with disabilities in Zimbabwe have been denied access to education due to negative attitudes of members of society and unfavorable cultural practices. However, few women with disabilities in Zimbabwe have broken the social barriers which hindered them from attaining education, and have achieved in life. Other females with disabilities, should imitate their colleagues who, despite, marginalization and stigmatization, managed to reach great heights in education, even the degree level.

Having critically analysed the challenges, prejudices, stereotypes and position of women with disabilities in society, the state and all stakeholders should work towards the empowerment of women with disabilities for them to be liberated from their plight. They should be extricated from all those entanglements that surround them. The state should take all appropriate measures to eliminate discrimination by any person, organization or private enterprise against women with disabilities in Zimbabwe. The voice of women with disabilities in Zimbabwe should be heard. They should also enjoy their Human Rights and fundamental Freedoms, including education, according to the (UNCRPD , Article 24 2006).Consequently, our dream and vision would come true as women with disabilities in Zimbabwe.

\section{References}

Chimedza, R. and Peters, S. (2001). Disability and education in an African context. Zimbabwe, College Press.

Coleridge, P. (2001). Disability, liberation and development. United Kingdom, Oxfam.

Danforth, S. and Rhodes, W. (1997). Disconstructing disability; A philosophy for inclusion, remedial and special education. New York, Palgrave.

Devlieger, P. J. (1998). Physical disability in Bantu languages; Understanding the relativity of classification and meaning. In Disability International Journal of rehabilitation research, 21, 63-70.

Freire, P. (1972). Pedagogy of the oppressed. Great Britain. Penguin books.

Haralambos, M. and Holborne. (2009) Sociology themes and perspectives. New Delhi. Oxford University.

Harris, A. (2003). Equality, and Human Rights. United Kingdom, Oxfam.

https://books. google.co.zw//books...illiteracy rate for disabled women... (18 February 2016).

Giddens, A. (2001). Sociology. 4th edition. Polity Press.

Global Health Action (2012). 5,18394 http://dx.doi,org/10.3402/gha.v5i0.18394.Disability in people affected by Leprosy: the role of impairment, activity, social participation, stigma and discrimination.

Kauffman, M.(1999).The illusion of full inclusion, New York. Pro-Ed.

Singal, N. (2003). Disability poverty and education. London, Routledge.

Stuart, O. (1992). Race and disability: “What type of double disadvantage?" Disability, Handicap and Society, Vol. 7, No. 2.

UNITED NATIONS CONVENTION ON THE RIGHTS OF PERSONS WITH DISABILITIES. (2006, December 13).

Zim-01, (1981). A study of children and adolescents with disabilities in Zimbabwe. 